\title{
The Impact of Community-Based Awareness Campaigns on the Early Breast Examination among Women at King Faisal University
}

\author{
Omama Al-Shehri \\ Collage of Medicine, King Faisal University, Al-Ahsa, Kingdome of Saudi Arabia \\ Email: Omama.a@hotmail.com
}

Received 6 July 2015; accepted 26 September 2015; published 29 September 2015

Copyright (C) 2015 by author and Scientific Research Publishing Inc.

This work is licensed under the Creative Commons Attribution International License (CC BY).

http://creativecommons.org/licenses/by/4.0/

(c) (i) Open Access

\section{Abstract}

Background and Objective: Breast cancer (BC) is the most common cancer between females in Saudi Arabia, the eastern area ranked as the first in the incidence rate. As the breast cancer awareness movement has expanded, majority of the new cases are still diagnosed in a later stage. This study aimed to evaluate the impact of breast cancer awareness campaigns on the knowledge and practice of early breast examination (EBE) which consisted of breast-self examination (BSE), clinical breast examination (CBE) and mammography, among women at King Faisal University. Methodology: A cross-sectional study carried out at King Faisal University, Al-Hassa city on a sample of 300 adult females from different urban and rural areas. A pre-tested, self-administered questionnaire was distributed to the participants. The questionnaire contains questions about: socio-demographic factors, awareness campaigns, practice and knowledge of breast cancer and early screening methods. Results: The age of the participants ranged from 16 to 60 years; $53 \%$ of the participants have attended campaigns; and $47 \%$ have never attended. Regarding the practice of BSE, CBE and mammography, the results were $8.8 \%, 3.3 \%$, and $4.3 \%$, respectively. The results show a significant relation between attending campaigns and good level of practice and knowledge. Conclusion and Recommendation: The findings indicate a great impact of the communitybased awareness campaigns on the practice of EBE. The study recommends a multilevel intervention for every age group, specially the age group that at risk.

\section{Keywords}

Breast, Cancer, Awareness, Campaigns, Examination, Mammography

\section{Introduction}

Breast cancer seems to be a huge global health problem. It is the most common cancer in women worldwide [1]

How to cite this paper: Al-Shehri, O. (2015) The Impact of Community-Based Awareness Campaigns on the Early Breast Examination among Women at King Faisal University. Open Journal of Preventive Medicine, 5, 400-408. 
[2]. Every year, about 1.5 million women around the world are diagnosed with breast cancer and about 502,000 die from it [2]. It is also the most common cancer in the Arabic gulf countries. There were about 11,000 breast cancer cases diagnosed between 1998 and 2007. It represents 11.8\% from cancers cases and 23.5\% from cancers in females in Gulf cooperation council (GCC) countries. The overall age standardized incidence rate (ASR) for all GCC countries women was 18.8 per 100,000 populations [3]. According to the Saudi Cancer Registry (SCR), breast cancer was the first malignancy between Saudi women; of all newly diagnosed female cancers in 2007, BC represented 26\% of them [4]. The breast cancer in the Kingdome of Saudi Arabia (KSA) has a mortality rate of $(10.4 / 100,000)$ and incidence rate of 22/100,000 [5]. Screening and early detection of breast cancer are important in reducing cancer morbidity and mortality [2] [6] [7]. National cancer organizations in the United States and Canada recommend mammograms annually [8] or every 1 to 2 years [9] [10]. However Tawfik Amin and colleagues [11] found that clinical breast examinations were done by less than $5 \%$ and mammography by only $3 \%$ of the participants. Another study in Riyadh [12] found that only $23.1 \%$ of the participants said that they practiced breast self-examination (BSE); $14.2 \%$ had clinical breast examination (CBE) and only 8.1\% did mammography before. Many researches have been conducted in Saudi Arabia showed that the knowledge of women regarding breast cancer and its screening was very low; one of them was applied on Saudi teachers in Buraidah; the results show that more than half of the women had a limited knowledge level [13]. Another study conducted in Al-Hassa city, [11] also found that the general knowledge about breast cancer screening and risk factors was low and it depended on the educational level. In the Arabic women population, living in urban area, young age, higher level of education, and family history of BC were positively associated with Breast Cancer Screening [14]. Other studies result in that a doctor's recommendation is a strong reason to do mammography [15]-[17]. However, the psychosocial barriers of early breast examination for Arabic women included fear of the screening process, fear of the mammography results, [14] [18], and concern that breast examination might threaten cultural and religious values [19]. The Supreme Council of Health in Qatar [4] recognized that lack of knowledge and awareness were major barriers to BCS. The council recommended awareness campaigns that focused on early diagnosis to educate the population about the signs and symptoms of breast cancer [14]. In Saudi Arabia, despite the lack of an organized screening program, there exist several programs/activities such as: the public awareness of breast cancer, through lectures, in a major hospital [20], a well-designed public awareness program, and the first organized population-based screening mammography program which was held in the Al Qassim region [21]. As the breast cancer awareness movement has expanded, an increasing number of voluntary organizations, governmental and private associations have sponsored activities related to Breast Cancer Awareness Month. Since 2009, more than 65,000 women visited breast cancer awareness campaigns in AlHassa city. Because there are few studies have been done regarding the community-based awareness campaigns in Saudi Arabia, we've start this study to evaluate the impact of breast cancer awareness campaigns on the knowledge and practice of early breast examination which consist of breast-self examination, clinical breast examination and mammography, among women at King Faisal university.

\section{Aim of the Study}

This study aimed to evaluate the impact of breast cancer awareness campaigns on the knowledge and practice of early breast examination, which consist of breast-self examination, clinical breast examination and mammography, among women at King Faisal University.

\section{Material and Method}

\subsection{Study Design}

A cross-sectional study that assessed the effect of the awareness campaigns on the knowledge and practice of early breast examination such as breast self examination (BSE), clinical breast examination (CBE) and mammography.

\subsection{Setting}

The study carried out at King Faisal University (KFU) in Al-Hassa Governorate, located in the Eastern Province of Saudi Arabia, between October and December 2013, among adult females from different urban and rural areas who work at KFU. 


\subsection{Participants}

This research was conducted on a sample of 300 women work at KFU, consisted of 150 students and 150 faculty members (75 administrators and 75 teachers) between the ages of 18 to 60 years, from different collages. The criteria of inclusion was: adult females who works at KFU and the criteria of exclusion was: females who are not willing to participate in the study. Since the estimated population size of the females who works at KFU during that selected period was about 20,000. We calculated a sample size of 300 based on the standard formula for simple random sampling, with a 95\% confidence level, 5.62\% confidence interval and response distribution of $50 \%$.

\subsection{Method of Data Collection}

A pre-tested, self-administered questionnaire that designed to investigate the research problem was distributed to the participants. The questionnaire contains 29 close-ended questions as the following: 1) Socio-Demographic factors: area of residence, age, marital status, Job (Student, Officer, Teacher) and field of working (medical, other). 2) 3 questions with answers of (Yes, No) about a history of any case in the breast, the first one asking if she has a relative or a friend with a breast cancer, the second one asking if she had a previous surgery in the breast and the third one asking if she have any disease in the breast. 3) 4 questions about awareness campaigns: Whether if she attended or not, reasons of not attending, effectiveness of these campaigns, and if she thinks that she's aware of early breast examination as a result of attending these campaigns. 4) 6 questions about early breast examination, the first question asked if she thinks that BSE is an effective way in early detection of BC, second question asked if she believes in the treatment of BC, the next 3 questions are about practicing BSE, $\mathrm{CBE}$ and mammography with answers of (yes, no, sometimes, I don't know what's BSE/CBE/mammography) and last question asking about the reasons of not doing CBE or mammography. 5) The last part of the questionnaire examined the knowledge through 11 questions some of them are written in a correct way the others are not, the answers was (yes, no, I don't know) they asked about prevalence of BC, risk factors (first pregnancy before 35, breastfeeding, Obesity), symptoms (nipple discharge or changes appear in the skin) and last 4 questions was about the correct time for early breast examination (BSE/CBE/mammography) and the procedure of BSE.

\subsection{Ethical Considerations}

Before the participants fill the questionnaire, a full explanation about the study was provided to them, they have been told that their participation is completely voluntary, and the data that have been taken from them were kept and no one had an access to it except for the researcher to insure the security of the participants, no names or personal information was taken from the participant like the address or the phone number. Statistical tests: Data coded and analyzed using SPSS version 22. Descriptive statistical analysis used to determine frequency description, $\mathrm{M}$ and $\mathrm{SD}$, chi-square test was used, categorical data were expressed using frequencies and percentage, $\mathrm{P}<$ 0.05 was applied as a level of significance.

\section{Results}

\subsection{Socio-Demographic and Participants Characteristics}

The age of the participants ranged from 16 to 60 years with mean of $(2.22 \pm 1.02)$, majority of them were below the age of risk, which is, 40 years old. Which gives an indication of the age groups distributions that work in the Saudi universities. More than $50 \%$ of the participants who have either a relative or friend with breast cancer or any history of a breast disease or had a previous breast surgery, had attended awareness campaigns (Table 1).

\subsection{Breast Cancer Awareness Campaigns}

Regarding the attendance of BC awareness campaigns, 159 (53\%) of the participants have attend campaigns at least once before and 141 (47\%) have never attend any BC awareness campaigns. Regarding the question: "reason could prevent you from attending a BC awareness campaigns", Majority of those who never attend campaigns chose "No enough advertisement" as their first reason, then "fear of cancer related activities" was the second reason, $52.5 \%$ of the participants chose the other answers as a reasons that could prevent them from attending campaigns. About the effectiveness of the campaigns in the awareness of early breast examination 
Table 1. Socio-demographic and participants characteristics.

\begin{tabular}{|c|c|c|c|c|c|c|}
\hline \multirow{2}{*}{ Character } & \multicolumn{2}{|c|}{ Attend } & \multicolumn{2}{|c|}{ Never attend } & \multicolumn{2}{|c|}{ Total } \\
\hline & (n) & $(\%)$ & (n) & $(\%)$ & (n) & (\%) \\
\hline Respondent & 159 & 53 & 141 & 47 & 300 & 100 \\
\hline \multicolumn{7}{|l|}{ Residance } \\
\hline Urban & 132 & 86.3 & 124 & 89.9 & 256 & 88 \\
\hline Rural & 21 & 13.7 & 14 & 10.1 & 35 & 12 \\
\hline \multicolumn{7}{|l|}{ Age } \\
\hline $16-20$ & 49 & 31 & 31 & 22 & 80 & 26.8 \\
\hline $21-30$ & 63 & 39.9 & 55 & 39 & 118 & 39.5 \\
\hline $31-40$ & 28 & 17.7 & 32 & 22.7 & 60 & 20.1 \\
\hline $41-50$ & 18 & 11.4 & 19 & 13.5 & 37 & 12.4 \\
\hline $51-60$ & - & - & 4 & 2.8 & 4 & 1.3 \\
\hline \multicolumn{7}{|l|}{ Marital status } \\
\hline Married & 65 & 41.1 & 72 & 52.2 & 137 & 46.3 \\
\hline Non-married & 93 & 58.9 & 66 & 47.8 & 159 & 53.7 \\
\hline \multicolumn{7}{|l|}{ Work } \\
\hline Student & 84 & 52.8 & 66 & 46.8 & 150 & 50 \\
\hline Officer & 39 & 24.5 & 36 & 25.5 & 75 & 25 \\
\hline Teacher & 36 & 22.6 & 39 & 27.7 & 75 & 25 \\
\hline \multicolumn{7}{|l|}{ Field of working } \\
\hline Medical & 55 & 34.8 & 24 & 17.1 & 79 & 26.5 \\
\hline Other & 103 & 65.2 & 116 & 82.9 & 219 & 73.5 \\
\hline \multicolumn{7}{|c|}{ Diseased relative or friend } \\
\hline Yes & 49 & 30.8 & 29 & 20.9 & 78 & 26.2 \\
\hline No & 110 & 69.2 & 110 & 79.1 & 220 & 73.8 \\
\hline \multicolumn{7}{|c|}{ Previous breast surgery } \\
\hline Yes & 6 & 3.8 & 4 & 2.9 & 10 & 3.3 \\
\hline No & 153 & 96.2 & 136 & 97.1 & 289 & 96.7 \\
\hline \multicolumn{7}{|c|}{ History of a breast disease } \\
\hline Yes & 19 & 11.9 & 5 & 3.5 & 24 & 8 \\
\hline No & 140 & 88.1 & 136 & 96.5 & 276 & 92 \\
\hline
\end{tabular}

n: number of participants who choose this answer. \%: percentage of participants who choose this answer.

(EBE), 87 (62.6\%) of the participants who had never attend campaigns chose "yes”, 107 (75.9\%) of them chose "yes" as an answer for the question that said "do you think breast-self examination is an effective way could help in early detection of BC?” and 114 (80.9\%) of them said "yes” as an answer for the last question in this part was asking about believing in the treatment of breast cancer. These results show the importance of solving the problems related to the reasons that prevent people from attending awareness campaigns as they seems the only barrier that affect attending (Table 2).

\subsection{Practice of Early Breast Examination}

Unfortunately results show that practicing the early breast examination methods is not affected by attending the awareness campaigns. Among the total sample, there was only $26(8.8 \%)$ who chose "Yes" for practicing of 
Table 2. Breast cancer awareness campaigns.

\begin{tabular}{|c|c|c|c|c|c|c|}
\hline \multirow{2}{*}{ Character } & \multicolumn{2}{|c|}{ Attend } & \multicolumn{2}{|c|}{ Never attend } & \multicolumn{2}{|c|}{ Total } \\
\hline & (n) & $(\%)$ & (n) & (\%) & (n) & (\%) \\
\hline \multicolumn{7}{|l|}{ Reason of not attending campaigns } \\
\hline I don't care & 12 & 9 & 27 & 19.4 & 39 & 14.3 \\
\hline $\mathrm{BC}$ is a normal case & 1 & 0.8 & 5 & 3.6 & 6 & 2.2 \\
\hline Bad location & 27 & 20.3 & 20 & 14.4 & 47 & 17.3 \\
\hline No enough advertisement & 32 & 24.1 & 40 & 28.8 & 72 & 26.5 \\
\hline Not reliable & 6 & 4.5 & 5 & 3.6 & 11 & 4 \\
\hline Fear & 28 & 21.1 & 29 & 20.9 & 57 & 21 \\
\hline Other reasons & 27 & 20.3 & 13 & 9.4 & 40 & 14.7 \\
\hline \multicolumn{7}{|c|}{ Effectiveness of these campaigns in the awareness of EBE } \\
\hline Yes & 142 & 91 & 87 & 62.6 & 229 & 77.6 \\
\hline No & 6 & 3.8 & 7 & 5 & 13 & 4.4 \\
\hline I don't know & 8 & 5.1 & 44 & 31.7 & 52 & 17.6 \\
\hline I don't know what's EBE & & & 1 & 0.7 & 1 & 0.3 \\
\hline \multicolumn{7}{|c|}{ Aware of EBE as a result of attending these campaigns } \\
\hline Yes & 104 & 75.4 & & & & \\
\hline No & 31 & 22.5 & & & & \\
\hline I don't know & 3 & 2.2 & & & & \\
\hline \multicolumn{7}{|c|}{ BES is an effective way in the early detection of $B C$} \\
\hline Yes & 137 & 86.2 & 107 & 75.9 & 244 & 81.3 \\
\hline No & 14 & 8.8 & 13 & 9.2 & 27 & 9 \\
\hline I don't know what's BSE & 8 & 5 & 21 & 14.9 & 29 & 9.7 \\
\hline \multicolumn{7}{|l|}{ Belief in the treatment of $\mathrm{BC}$} \\
\hline Yes & 146 & 91.8 & 114 & 80.9 & 260 & 86.7 \\
\hline No & 4 & 2.5 & 5 & 3.5 & 9 & 3 \\
\hline I don't know & 9 & 5.7 & 22 & 15.6 & 31 & 10.3 \\
\hline
\end{tabular}

EBE: early breast examination. BSE: breast self examination. CBE: clinical breast examination. BC: breast cancer.

BSE, 10 (3.3\%) chose "Yes” for CBE and only 13 (4.3\%) said that they do mammography annually. Regarding the reasons of not doing CBE or screening by mammogram, “my doctor didn't suggest” was the first reason as $65(23 \%)$ chose it as the reason that make them not practicing or screening (Table 3 ).

\subsection{Knowledge of Early Breast Examination}

Table 4 shows the responses of the participants toward the knowledge items of EBE. Generally, the number of the participants who answered correctly from those who attend campaigns is more than the number of those who answered correctly from participants who never attend, which shows The effect of attending campaigns on the knowledge about EBE.

Table 5 shows the results of the analytical test that applied to see the relation between the variables, the results showed that the practice of BSE, CBE and mammography is influenced by attending campaigns. Regarding the knowledge items, the results also show that there is a positive relation between attending campaigns and choosing the correct answer except for the third statement the says "Breastfeeding can reduce the risk of BC" which has a $\mathrm{P}$ value $>0.05$. 
Table 3. Practice of early breast examinations.

\begin{tabular}{|c|c|c|c|c|c|c|}
\hline \multirow{2}{*}{ Character } & \multicolumn{2}{|c|}{ Attend } & \multicolumn{2}{|c|}{ Never attend } & \multicolumn{2}{|c|}{ Total } \\
\hline & (n) & $(\%)$ & (n) & $(\%)$ & (n) & $(\%)$ \\
\hline \multicolumn{7}{|l|}{ Practice of BSE } \\
\hline Yes & 17 & 10.9 & 9 & 6.4 & 26 & 8.8 \\
\hline Sometimes & 73 & 46.8 & 37 & 26.2 & 110 & 37 \\
\hline No & 59 & 37.8 & 68 & 48.2 & 127 & 42.8 \\
\hline I don't know what's BSE & 7 & 4.5 & 27 & 19.1 & 34 & 11.4 \\
\hline \multicolumn{7}{|l|}{ Gradually visiting doctor for CBE } \\
\hline Yes & 9 & 5.7 & 1 & 0.7 & 10 & 3.3 \\
\hline Sometimes & 15 & 9.4 & 14 & 9.9 & 29 & 9.7 \\
\hline No & 127 & 79.9 & 103 & 73 & 230 & 76.7 \\
\hline I don't know what's CBE & 8 & 5 & 23 & 16.3 & 31 & 10.3 \\
\hline \multicolumn{7}{|l|}{ Annual screening by mammoghram } \\
\hline No & 121 & 76.6 & 105 & 74.5 & 226 & 75.6 \\
\hline Yes & 11 & 7 & 2 & 1.4 & 13 & 4.3 \\
\hline Once before & 8 & 5.1 & 7 & 5 & 15 & 5 \\
\hline I don't know what's mammogram & 18 & 11.4 & 27 & 19.1 & 45 & 15.1 \\
\hline \multicolumn{7}{|c|}{ Reason of not doing CBE or mammography } \\
\hline No reason prevent me & 11 & 7.4 & 7 & 5.2 & 18 & 6.4 \\
\hline Fear of wrong diagnosis & 21 & 14.1 & 25 & 18.7 & 46 & 16.3 \\
\hline My doctor didn't suggest & 31 & 20.8 & 34 & 25.4 & 65 & 23 \\
\hline Too young to care about it & 21 & 14.1 & 19 & 14.2 & 40 & 14.1 \\
\hline I don't have time & 24 & 16.1 & 29 & 21.6 & 53 & 18.7 \\
\hline The cost & 4 & 2.7 & 3 & 2.2 & 7 & 2.5 \\
\hline BSE is enough & 37 & 24.8 & 17 & 12.7 & 54 & 19.1 \\
\hline
\end{tabular}

Table 4. Knowledge of early breast examinations.

\begin{tabular}{|c|c|c|c|c|c|c|c|c|c|}
\hline \multirow{2}{*}{ Informations } & \multicolumn{3}{|c|}{ Attend } & \multicolumn{3}{|c|}{ Never attend } & \multicolumn{3}{|c|}{ Total } \\
\hline & $(\checkmark)$ & $(\times)$ & (!) & $(\checkmark)$ & $(\times)$ & (!) & $(\checkmark)$ & $(\times)$ & (!) \\
\hline $\mathrm{BC}$ is the most common cancer in females in $\mathrm{KSA} /$ true. & 51.9 & 5.1 & 43 & 38.6 & 3.6 & 57.9 & 45.6 & 4.4 & 50 \\
\hline $\begin{array}{l}\text { First pregnancy before the age of } 35 \text { can reduce the risk of } \\
\text { BC/true. }\end{array}$ & 35.8 & 5 & 59.1 & 24.5 & 2.2 & 73.4 & 30.5 & 3.7 & 65.8 \\
\hline Breastfeeding can reduce the risk of $\mathrm{BC} /$ true. & 76.7 & 2.5 & 20.8 & 70.3 & 2.2 & 27.5 & 73.3 & 2.4 & 23.9 \\
\hline BSE must be done every 3 months/false. & 27.2 & 23.4 & 49.4 & 23 & 10.8 & 66.2 & 23.2 & 19.5 & 57.2 \\
\hline Women above the age of $\mathbf{4 0}$ should do mammogram annually/true. & 71.1 & 2.5 & 26.4 & 54 & 2.9 & 43.2 & 63.1 & 2.7 & 34.2 \\
\hline CBE most be done every month/false. & 31.4 & 18.2 & 50.3 & 22.9 & 15.7 & 61.4 & 20.4 & 24.1 & 55.5 \\
\hline The best time for BSE is during the menstrual period/false. & 42.8 & 22.6 & 34.6 & 23 & 15.1 & 61.9 & 22.8 & 29.9 & 47.3 \\
\hline BSE is done by looking into the breast without touching them/false. & 75.5 & 8.2 & 16.4 & 10.8 & 45.3 & 43.9 & 9.4 & 61.4 & 29.2 \\
\hline Obesity is a risk factor that increases the incidence of $\mathrm{BC} / \mathrm{true}$. & 39.9 & 7.6 & 52.5 & 25.9 & 12.2 & 61.9 & 33.3 & 9.8 & 56.9 \\
\hline Nipple discharge rather than milk could be a symptom of BC/true. & 60.8 & 7 & 32.3 & 37.9 & 10 & 52.1 & 50 & 8.4 & 41.6 \\
\hline Changes in the skin could be a symptom of BC/true. & 47.5 & 8.9 & 43.7 & 29.3 & 8.6 & 62.1 & 38.9 & 8.7 & 52.3 \\
\hline
\end{tabular}

$(\checkmark)$ : The percentage of participants who choose the right answer. $(\times)$ : The percentage of participants who choose the wrong answer. (!) The percentage of participants who choose the answer "I don't know". 
Table 5. Shows the results of the analytical test that applied to see the relation between the variables, the results showed that the practice of BSE, CBE and mammography is influenced by attending campaigns. Regarding the knowledge items, the results also show that there is a positive relation between attending campaigns and choosing the correct answer except for the third statement the says "breastfeeding can reduce the risk of $\mathrm{BC}$ ” which has a $\mathrm{P}$ value $>0.05$.

\begin{tabular}{|c|c|c|}
\hline & Chi-square & (p) \\
\hline \multicolumn{3}{|l|}{ Practice } \\
\hline BSE & 25.954 & 0.000 \\
\hline CBE & 15.172 & 0.002 \\
\hline Mammoghraphy & 8.290 & 0.040 \\
\hline \multicolumn{3}{|l|}{ Knowledge } \\
\hline $\mathrm{BC}$ is the most common cancer in females in $\mathrm{KSA} /$ true & 6.528 & 0.038 \\
\hline First pregnancy before the age of 35 can reduce the risk of $\mathrm{BC} /$ true & 7.102 & 0.029 \\
\hline Breastfeeding can reduce the risk of $\mathrm{BC} /$ true & 1.873 & 0.392 \\
\hline BSE must be done every 3 months/false & 13.874 & 0.001 \\
\hline Women above the age of $\mathbf{4 0}$ should do mammogram annually/true & 9.558 & 0.008 \\
\hline CBE most be done every month/false & 10.087 & 0.006 \\
\hline The best time for BSE is during the menstrual period/false & 30.667 & 0.000 \\
\hline BSE is done by looking into the breast without touching them/false & 30.774 & 0.000 \\
\hline Obesity is a risk factor that increase the incidence of $\mathrm{BC} /$ true & 7.092 & 0.029 \\
\hline Nipple discharge rather than milk could be a symptom of $\mathrm{BC} /$ true & 15.642 & 0.000 \\
\hline Changes in the skin could be a symptom of BC/true & 11.150 & 0.004 \\
\hline
\end{tabular}

\section{Discussion}

As this study aimed to evaluate the impact of the awareness campaigns, a better knowledge and practice have been observed in the participants who attend awareness campaigns. The results showed that the attendance is not related to any socio-demographic characteristics. Other factors like a diseased relative or friend and a previous breast disease or surgery also seems that it has no relation with attending campaigns. The attendance of campaigns in our study was lower than the attendance in a Similar study in Ghana [22], which reported that From the 131 participants of the intervention community, 127 (97\%) reported having attended the BC awareness program. The same study has a different results regarding the factors that affect the attendance, Participants from the intervention community reported more family history of breast cancer and previous history of breast disease than those from the referent community. Regarding the reason of not attending these campaigns, our study results showed that $26.5 \%$ of the study sample chose "No enough advertisement" as a reason could prevent them, which indicate the good willing of most the females to attend campaigns, "Fear from these activities" represent only $21 \%$ of the total sample which is agreed with a study applied on Arab women in Israel which says that personal, psychological, environmental factors influence participation in screening programs and other screening activities [23]. Our study results showed that $81.3 \%$ of the participants agreed that BSE is an effective way in early detection of BC which is similar to the results of Ghana's study [22] that accept BSE as a useful way for finding the disease early. Regarding the practice of EBE and in the same previous study that applied on women from Ghana [22], the results showed percentage of practicing among women who attend the intervention equal to $86.3 \%$ which is higher than our result that equal $10.9 \%$ for those who practice gradually and $46.8 \%$ for those who chose "sometime". According CBE and mammogram practicing among adult females included in our study, results showed a high numbers compared with a study applied in Al-Hassa city [11] that reported a practicing percentage equal to 5\% according to $\mathrm{CBE}$ and $3 \%$ regarding mammography between the participants. As a reason of not doing CBE or mammography, 23\% of the total sample chose "My doctor didn't suggest that" which is lower than a similar study that applied in Riyadh [12], in which the majority of the participants with a percentage of $92.6 \%$ chose "physician recommendation" as a strong reason to apply screening, another study [24] found that Physician recommendation is a strong predictor to perform early detection methods. While "fear of 
mammography” represent only $16.3 \%$ of the total sample, it was a strong barrier according that represent $54.9 \%$ of the adult female in Qatar [14]. There was a very clear difference regarding the knowledge of BC between participants who attend campaigns and those who didn’t. In 7 questions out of 11, the "I don't know" choice took a percentage of $45 \%$ to $65 \%$ of the overall answers. $73.3 \%$ of the total sample chose the correct answer in the statement that says "Breastfeeding can reduce the risk of BC" which indicate the effect of the religious culture that recommends breastfeeding. The results of a similar study [11] shows a percentage of $77 \%$ of the participants chose the correct answer regarding the prevalence of BC which is more than the result of the present study that equal $45.6 \%$ of correct answers among the total sample. But at the same previous study an information about the annual screening by mammography has got a percent of $31.3 \%$ of the correct answers which is lower than the result of our study that shows a percent of $63.1 \%$ of the correct answers. Regarding the statement that says "Obesity is a risk factor" the result were similar in both the previous [11] and present study with percent of 35\%, 33.3\% respectively. The P-value's of the influence of attendance on the knowledge and practice of EBE, have strongly approved the hypothesis of the study that says there's an effect of attending campaigns on the knowledge about BC and practice of EBE, which is also reported by other studies in Ghana and Qatar [22] [25]. The results of this study are affected by some limitations; one of them is lack of available and reliable data about the number of the awareness campaigns that were held inside the university or outside it and number of the attending population of the campaigns. The reason of this limitation is the lack of statistical departments in the sponsored organizations or associations. But as this awareness movement is still growing, an estimated number of attending populations has been taking from a governmental organization as it is the only available data. Another limitation is that the majority of the participants are below that the age of risk of having breast cancer (40 years old), and this is mainly because of the age groups distribution that works in Saudi universities as most of them are below the age of 40 years old. Although this study has its own limitations, it is the first study in Saudi Arabia that assess the effect of the awareness campaigns on different aspects that related to early detection of breast cancer, which will help in improving the health educations and screening programs and designing an appropriate programs for different age groups in the country.

\section{Conclusion}

The findings indicate a great impact of the community-based awareness campaigns on the practice of early breast examination such as breast-self examination, clinical breast examination and mammography; also it affects the knowledge regarding these methods, symptoms of breast cancer, risk factors, procedure and the right time for screening. Although the attendances of the campaigns were almost half of the participants, the majority of the attendances were below the age of risk (40 years).

\section{Recommendations}

The study recommend a multilevel intervention for every age group in the population, and specially the age group that at risk to overcome the increasing number of the new cases which diagnosed in later stage, more research is needed to identify the barriers associated with different ages and to determine the special needs for different groups in the population which can help in a designing an appropriate types of intervention according to each group in the population fore example lectures, seminars, workshop and face-to-face interviews, such different type of awareness activity can rise the level of awareness and reduce the fear related to cancer activities or screening methods or even results of these early-detection methods which help in the early detection of the disease and better prognosis.

\section{Acknowledgements}

This study was made possible by the help and advice of: Dr. Ibtisam Ahmad, Dr. Hanem Mostafa, Dr. sayed Ibrahim, Dr. Edjit Nambiar, Dr. Omar Bayameen and Dr. Aysha Al-Abdulqader.

\section{References}

[1] Health Canada (2004) Health Canada: Breast Cancer. It’s Your Health. Ministry of Health, Ottawa.

[2] WHO (2010) World Health Organization (WHO): Cancer. http://www.who.int/

[3] Ten-Year Cancer Incidence among Nationals of the GCC States 1998-2007. http://www.moh.gov.bh/pdf/publications 
[4] Dandash, K.F. and Al-Mohaimeed, A. (2007) Knowledge, Attitudes, and Practices Surrounding Breast Cancer and Screening in Female Teachers of Buraidah, Saudi Arabia. International Journal of Health Sciences (Qassim), 1, 61-71.

[5] WHO (2008) International Agency for Research on Cancer (IARC): World Cancer Report 2008 and Global Cancer Statistics. http://www.iarc.fr/en/publications/pdfs-online/wcr/2008/index.php

[6] Haji-Mahmoodi, M., Montazeri, A., Jarvandi, S., Ebrahimi, M., Haghighat, S. and Harirchi, I. (2002) Breast Self Examination: Knowledge, Attitudes, and Practice among Female Health Care Workers in Tehran, Iran. Breast Journal, 8, 222-225. http://dx.doi.org/10.1046/j.1524-4741.2002.08406.x

[7] Elmore, J.G., Armstrong, K., Lehman, C.D. and Fletcher, S.W. (2005) Screening for Breast Cancer. Journal of the American Medical Association, 293, 1245-1256. http://dx.doi.org/10.1001/jama.293.10.1245

[8] ACS (2010) American Cancer Society (ACS): American Cancer Society Guidelines for the Early Detection of Cancer. http://www.cancer.org

[9] CCS (2011) Canadian Cancer Society (CCS): Breast Cancer. http://www.cancer.ca

[10] NCI (2010) National Cancer Institute (NCI): National Cancer Institute Fact Sheet: Mammograms. http://www.cancer.gov

[11] Amin, T., AlMulhim, A. and AlMeqihwi, A. (2009) Breast Cancer Knowledge, Risk Factors and Screening among Adult Saudi Women in a Primary Health Care Setting. Asian Pacific Journal of Cancer Prevention, 10, 1-4.

[12] Ravichandran, K., Al-Hamdan, N. and Mohamed, G. (2011) Knowledge, Attitude, and Behavior among Saudis toward Cancer Preventive Practice. Journal of Family and Community Medicine, 18, 135-142. http://dx.doi.org/10.4103/2230-8229.90013

[13] Dandash, K. and Al-Mohaimeed, A. (2007) Knowledge, Attitudes and Practice Surrounding Breast Cancer and Screening in Female Teachers of Buraidha, Saudi Arabia. International Journal of Health Sciences, 1, 61-71.

[14] Bener, A., El Ayoubi, H.R., Moore, M.A., Basha, B., Joseph, S. and Chouchane, L. (2009) Do We Need to Maximise the Breast Cancer Screening Awareness? Experience with an Endogamous Society with High Fertility. Asian Pacific Journal of Cancer Prevention, 10, 599-604.

[15] Donnelly, T.T., Al-Khater, A., Al-Kuwari, M., Singh, R., Bujassoum, A.S., Malik, M., Al-Meer, N., Chaudhry, S. and Dorry, R. (2012) Breast Cancer Screening amongst Arabic Women Living in the State of Qatar: Awareness, Knowledge, and Participation in Screening Activities. Avicenna 2012. http://www.qscience.com/doi/abs/10.5339/avi.2012.2

[16] Azaiza, F. and Cohen, M. (2006) Health Beliefs and Rates of Breast Cancer Screening among Arab Women. Journal of Women's Health, 15, 520-530. http://dx.doi.org/10.1089/jwh.2006.15.520

[17] O’Malley, M.S., Earp, J.A., Hawley, S.T., Chell, M.I., Matthews, H.F. and Mitchell, J. (2001) The Association of Race/Ethnicity, Socioeconomic Status, and Physician Recommendation for Mammography: Who Gets the Message about Breast Cancer Screening? American Journal of Public Health, 91, 49-54. http://dx.doi.org/10.2105/AJPH.91.1.49

[18] Supreme Council of Health (2011) National Cancer Strategy: The Path to Excellence, 2011-2016. Qatar.

[19] Al-Omran, H. (2005) Measurement of the Knowledge, Attitudes, and Beliefs of Arab-American Adults toward Cancer Screening and Early Detection: Development of a Survey Instrument. Ethnicity \& Disease, 15, 15-16.

[20] Arshad, S., Williams, K.P., Mabiso, A., Dey, S. and Soliman, A.S. (2010) Evaluating the Knowledge of Breast Cancer Screening and Prevention among Arab-American Women in Michigan. Journal of Cancer Education, 26, 135-138. http://dx.doi.org/10.1007/s13187-010-0130-X

[21] Shah, S., Ayash, C., Pharaon, N.A. and Gany, F. (2008) Arab American Immigrants in New York: Health Care and Cancer Knowledge, Attitudes, and Beliefs. Journal of Immigrant and Minority Health, 10, 429-436. http://dx.doi.org/10.1007/s10903-007-9106-2

[22] Mena, M., Wiafe-Addai, B., Sauvaget, C., Ali, I., Wiafe, S., Dabis, F., Anderson, B., Malvy, D. and Sasco, A. (2014) Evaluation of the Impact of a Breast Cancer Awareness Program in Rural Ghana: A Cross-Sectional Survey. International Journal of Cancer, 134, 913-924.

[23] Soskolne, V., Marie, S. and Manor, O. (2007) Beliefs, Recommendations and Intentions Are Important Explanatory Factors of Mammography Screening Behavior among Muslin Arab Women in Israel. Health Education Research, 22, 665-676. http://dx.doi.org/10.1093/her/cyl132

[24] Friedman, L.C., Puryear, L.J., Moore, A. and Green, C.E. (2005) Breast and Colorectal Cancer Screening among LowIncome Women with Psychiatric Disorders. Psycho-Oncology, 14, 786-791. http://dx.doi.org/10.1002/pon.906

[25] Donnelly, T. and Hwang, J. (2015) Breast Cancer Screening Interventions for Arabic Women: A Literature Review. Journal of Immigrant and Minority Health, 17, 925-939. 